\title{
Belongingness is a Mediating Factor Between Religious Service Attendance and Reduced Psychological Distress During the COVID-19 Pandemic
}

\author{
Jay L. Michaels ${ }^{1}$ (D) $\cdot$ Feng Hao $^{1} \cdot$ Nicole Ritenour $^{1} \cdot$ Naomi Aguilar $^{1}$
}

Accepted: 8 December 2021 / Published online: 24 January 2022

(c) The Author(s), under exclusive licence to Springer Science+Business Media, LLC, part of Springer Nature 2021

\begin{abstract}
This study aimed to test whether pre-pandemic religious service attendance relates to both lesser impact from the COVID-19 pandemic and lower levels of psychological distress among a sample of 645 American adults across nine US regions. A second aim was to test whether belongingness mediated these relationships. First, it was expected that more frequent pre-pandemic religious service attendance relates to belongingness, which mediates the religious service attendance and psychological distress association. Second, it was expected that people who felt greater belongingness also experienced less perceived impact from the pandemic. Results from a path model supported these hypotheses. This is among the first studies to provide empirical evidence for religion's association with psychological distress during the COVID-19 pandemic.
\end{abstract}

Keywords Religion · Belongingness · COVID-19 · Psychological distress · Wellbeing

\section{Introduction}

For many people, the first half of 2020 was accompanied by fear, stress, and anxiety as the novel coronavirus quickly emerged as a pandemic. This is evident in the USA, considering that $36.1 \%$ of Americans reported symptoms of anxiety or depression by early June, 2020, and that this percentage increased to $40.9 \%$ by mid-July (Centers for Disease Control, 2020). In the USA and in many other countries, these increased levels of psychological distress may relate to the widespread enactment of social distancing policies that closed social gathering places and encouraged, or

\section{Jay L. Michaels}

jaymichaels@usf.edu

1 Department of Psychology, University of South Florida Sarasota-Manatee, 8350 N. Tamiami Trail, Sarasota, FL 34243, USA 
in some cases mandated, that people remain at home unless traveling for essential reasons (e.g., Marroquín et al., 2020). Although social distancing helps to control pathogen transmission (e.g., Ahmed et al., 2018; Wilder-Smith \& Freedman, 2020), it also detrimentally impacts people's social connectedness and contributes to a sense of isolation, loneliness, diminished coping capacity, and heightened risk of both minor and major psychiatric disorders (e.g., González-Sanguino et al., 2020; Huang \& Zao, 2020; Li \& Wang, 2020). In addition, social isolation is a known risk factor linked to numerous chronic illnesses even when controlling for other factors (for review see Cacioppo \& Cacioppo, 2014). Moreover, people who feel socially isolated and lonely are more susceptible to infection (e.g., Miller, 2011) and have higher mortality risk (e.g., Holt-Lundstad et al., 2015).

Although social distancing can help a community avoid an escalating rate of infectious disease transmission, it is also a psychologically unpleasant experience that can contribute to psychological distress, thus impacting health and wellbeing. With social distancing being a necessity during the pandemic, it is vital that researchers and health practitioners better understand how different factors relate to worsened versus alleviated psychological distress related to social distancing.

From theory and empirical evidence, religion is one factor that might help buffer against psychological distress even when people are socially isolated. This idea follows from religion's capacity to enhance people's sense of belongingness (Crescioni \& Baumeister, 2013; Graham \& Haidt, 2010) that extends beyond immediate, direct religious community involvement. If religion helps people maintain a sense of belongingness, are people who are involved in religious communities better able to cope with the pandemic and avoid significant psychological distress during social distancing? This study aims to address this question by providing some of the first empirical information about whether, and how, religion has implications for psychological distress during the COVID-19 pandemic.

\section{Religious Community Involvement}

\section{Direct Benefits}

Foremost, many studies have established that religious community involvement relates to diminished distress including reduced rates of depression and better mental health (e.g., Balbuena et al., 2013; Brewer et al., 2014; Keyes \& Reitzes, 2007). Abundant evidence further supports a link between religious involvement and wellbeing in general (e.g., Strawbridge et al., 2001; VanderWeele, 2017). The relationships between religious community involvement and both reduced psychological distress and enhanced well-being have been explained by objective and subjective social factors. Social support is a primary objective social factor known to play a role in health and well-being (House et al., 1988) and is enhanced when people have larger social networks that afford greater potential for others to provide instrumental assistance and meaningful social interaction (see George et al., 2002). Evidence supports that the social support people gain through religious community involvement contributes to decreased distress and increased well-being (Brewer et al., 2014; 
Byrd et al., 2000; Ellison et al., 1989; Kim-Yeary et al., 2012). Yet, scholarship also reveals that subjective and indirect social factors that emerge from religious involvement also play a role in religion's relationship to distress reduction.

\section{Indirect Benefits}

By being involved in a religious community, people experience a variety of indirect social benefits that can contribute to better capacity to cope, reduced psychological distress, and general well-being (see Ellison, 1991). Some of these include greater cognitive coherence about important beliefs and values (e.g., Crescioni \& Baumeister, 2013), enhanced clarity about one's identity (e.g., Keyes \& Reitze, 2007; Krause \& Wulff, 2005), and perception of subjective social as well as emotional support (e.g., Dunbar, 2020; George et al., 2002).

These indirect social benefits allow religious communities to fulfill fundamental human needs, including those related to belongingness and affiliation (Crescioni \& Baumeister, 2013; Krause \& Wulff, 2005) even when people are unable to physically attend religious services. For example, people who belong to a religious community have a mere perception that they are valued by a community of like-minded, caring others, and this enhances perceived support. This indirect sense of support gained through perceived belongingness is thought to be one reason religious community involvement relates to well-being and diminished psychological distress even outside of social contact (e.g., Hill et al., 2011; Keyes \& Reitez, 2005). Thus, scholarship provides evidence that even with social distancing and not attending religious services physically, people who are involved in religious communities may still be psychologically equipped to better cope with the pandemic. Consequently, people who are religiously involved may experience less psychological distress through religion's unique capacity to fulfill belongingness needs (see Crescioni \& Baumeister, 2013). This possibility is further supported by some studies that demonstrate that a variety of psychological factors mediate the link between religious service attendance and well-being (e.g., Ellison, 1991; Krause \& Wulff, 2005; Steffen et al., 2017), showing that directly participating in a communal religious activity is not the lone factor contributing to the religion and reduced distress association.

Considering how religious community involvement relates to diminished distress and enhanced well-being, does religion and its contribution to perceived belongingness relate to diminished psychological distress during the COVID-19 pandemic? Leading scholars have speculated that this association should exist (e.g., Dein et al., 2020), with some drawing on the evidence to highlight the ways people can leverage both social and personal facets of religion to promote mental health and buffer against psychological distress during this event (e.g., Koenig, 2020; Peteet, 2020). Yet, with the pandemic being a recent event, there is a lack of empirical data regarding the religion-psychological distress link during the COVID-19 pandemic (see Dein et al., 2020). The present study responds to the lack of evidence by analyzing some of the first data about how religion relates to both belongingness and 
psychological distress among a national sample of Americans who were social distancing in early June 2020.

\section{Study Hypotheses}

This study tests two hypotheses motivated by theory and evidence about the association between religion and psychological distress. First, it is expected that people who were involved in frequent religious service attendance prior to the pandemic experience a greater sense of belongingness, and this belongingness mediates the relationship between religious service attendance and diminished psychological distress (Hypothesis 1). Second, the enhanced belongingness people gain from previous religious service attendance relates to a lower perceived impact from the COVID-19 pandemic, which further contributes to well-being (Hypothesis 2).

\section{Method}

\section{Participants}

Data were collected online between June 3 and 11, 2020, using a Qualtrics panel sample of $N=645$ American adults, all of whom indicated consent prior to participating. There were participants from all 50 states, although the largest samples were from California (14.4\%), Florida (10.5\%), New York (6.4\%), and Texas (4.3\%); see Table 1 for demographic information. There was near equal representation of women $(50.7 \%)$ and men $(49.1 \%)$ (one participant identified "other" for sex), and most participants were middle-aged or older adults (age $M=64.43$, $S D=11.39$; see Table 2). Most participants lived in suburban areas $(52.1 \%)$ with fewer reporting an urban (18.6\%) or rural $(29.3 \%)$ area as their main place of residence. Among the participants, $60.3 \%$ reported never attending religious services; $39.7 \%$ reported attending at least once per year. This aligns well with the fact that $50.7 \%$ of the sample identified as nonreligious, while the remaining $49.3 \%$ reported following some form of religion. Of these people, most reported Christianity (43.9\%) as their religion, with others reporting Judaism (2.8\%), Buddhism $(0.5 \%)$, or some other religion (2.2\%). Data on specific Christian denomination were not obtained. Significantly, among those who reported attending religious services in the past year, a majority (95\%) had not attended any in-person services during the past week, suggesting that most participants were engaged in some level of social distancing. This is further validated by considering that the vast majority of participants had not engaged in common social behaviors during the past week aside from visiting friends/family, which could include people that they lived with (see Table 3). 
Table 1 Demographic characteristics

\begin{tabular}{|c|c|c|c|}
\hline Variable & $M$ & $S D$ & Frequencies \\
\hline Sex & - & - & $\begin{array}{l}\text { Men }=317 \\
\text { Women = } 327 \\
\text { Other }=1\end{array}$ \\
\hline Age & 64.43 & 11.39 & (see Table 2) \\
\hline Geographic Region* & - & - & $\begin{array}{l}\text { New England }=30 \\
\text { Mid Atlantic }=97 \\
\text { South }=157 \\
\text { Midwest }=126 \\
\text { Great Plains }=16 \\
\text { Rocky Mountain = } 24 \\
\text { Southwest }=63 \\
\text { Pacific Coast }=126 \\
\text { Alaska/Hawai' } i=6\end{array}$ \\
\hline Rural/Urban & - & - & $\begin{array}{l}\text { Rural }=189 \\
\text { Suburban }=336 \\
\text { Urban }=120\end{array}$ \\
\hline Type of Religion ${ }^{* *}$ & - & - & $\begin{array}{l}\text { Christianity }=283 \\
\text { Judaism }=18 \\
\text { Buddhism }=3 \\
\text { No Religion }=327 \\
\text { Other }=14\end{array}$ \\
\hline $\begin{array}{l}\text { Frequency of Religious Service } \\
\text { Attendance }\end{array}$ & 2.39 & 2.02 & $\begin{array}{l}\text { Never }=389 \\
\text { Once per year }=37 \\
\text { A few times per year }=73 \\
\text { Once per month }=12 \\
\text { A few times per month }=18 \\
\text { Once per week }=93 \\
\text { More than once per week }=23\end{array}$ \\
\hline
\end{tabular}

*All participants were from the USA; the frequency of participants residing in different geographic locations within this nation is noted

**Other religions were included in the survey (e.g., Islam), but no participants identified these other religions, thus they are omitted from this table. No additional demographic variables were obtained to maintain survey brevity and because other variables were not theoretically expected to relate to the key components of the model

\section{Measures}

In addition to the previously described demographic information, data included the following measures. First, participants indicated how frequently they attended religious services during the past year using a Likert scale coded $1=$ "never" to $7=$ "more than once per week."1

Belongingness was assessed using the General Belongingness Scale (Malone et al., 2012), which features 13 statements participants respond to using a Likert

\footnotetext{
1 The religious service attendance measure was coded $1=$ "never," $2=$ "once per year," $3=$ "a few times per year," $4=$ "once per month," $5=$ "a few times per month," $6=$ "once per week," and $7=$ "more than once per week.".
} 
Table 2 Descriptive statistics for main study variables for the entire sample, religious versus nonreligious participants, and based on age group

\begin{tabular}{|c|c|c|c|c|c|}
\hline \multirow[t]{2}{*}{ Group } & \multirow[t]{2}{*}{$N(\%)$} & \multirow{2}{*}{$\begin{array}{l}\text { Religious Ser- } \\
\text { vice Attendance } \\
M(S D)\end{array}$} & \multirow{2}{*}{$\begin{array}{l}\text { Belongingness } \\
M(S D)\end{array}$} & \multirow{2}{*}{$\begin{array}{l}\text { COVID-19 Impact } \\
M(S D)\end{array}$} & \multirow{2}{*}{$\begin{array}{l}\text { Psychological } \\
\text { Distress } \\
M(S D)\end{array}$} \\
\hline & & & & & \\
\hline Full Sample & $645(100 \%)$ & $2.39(2.02)$ & $61.40(12.68)$ & $2.88(.82)$ & $29.53(9.25)$ \\
\hline \multicolumn{6}{|c|}{ Descriptive statistics based on religious status } \\
\hline Religious & $318(49.3 \%)$ & $3.66(2.17)$ & $63.83(12.16)$ & $2.71(.83)$ & $29.08(9.48)$ \\
\hline Non-religious & $327(50.7 \%)$ & $1.15(.66)$ & $59.04(12.75)$ & $2.94(.81)$ & $29.97(9.01)$ \\
\hline \multicolumn{6}{|c|}{ Descriptive statistics based on age group } \\
\hline 18 to 29 & $4(.6 \%)$ & $1.75(1.50)$ & $46.50(10.08)$ & $3.50(.58)$ & $41.25(17.48)$ \\
\hline 30 to 39 & $24(3.7 \%)$ & $2.17(1.79)$ & $56.08(12.13)$ & $3.33(.76)$ & $36.58(15.36)$ \\
\hline 40 to 49 & $46(7.1 \%)$ & $2.07(1.79)$ & $55.43(14.30)$ & $2.87(.65)$ & $35.67(12.62)$ \\
\hline 50 to 59 & $96(14.9 \%)$ & $2.35(1.96)$ & $59.52(14.11)$ & $2.90(.79)$ & $29.21(8.48)$ \\
\hline 60 to 69 & $249(38.6 \%)$ & $2.43(2.09)$ & $62.10(12.10)$ & $2.85(.84)$ & $28.81(8.90)$ \\
\hline 70 or older & $226(35.0 \%)$ & $2.45(2.06)$ & $63.47(11.70)$ & $2.85(.84)$ & $28.26(7.02)$ \\
\hline
\end{tabular}

scale anchored by $1=$ "strongly disagree" to $7=$ "strongly agree." Some sample items from the scale include, "When I am with other people, I feel included," and "I feel isolated from the rest of the world" (reverse-coded). The General Belongingness Scale had excellent reliability $(\alpha=0.95)$.

Participants were also asked to indicate "overall, how significantly has COVID19 impacted your daily life?" Responses ranged from $1=$ "no impact at all" to $4=$ "significant impacts." This provided a single-item measure of perceived COVID19 impact.

Finally, psychological distress was assessed using the Depression Anxiety Stress Scale (DASS) 21-item short form version (see Antony et al., 1998). This scale measures anxiety, depression, and tension-related stress where higher scores indicate that a person is experiencing more distress in their life. Participants answered based on how they felt during the past week and responded to statements such as, "I felt that I had nothing to look forward to," and "I felt scared without any good reason." The DASS also exhibited excellent reliability $(\alpha=0.94)$. Variable descriptive statistics for the full sample, for religious versus nonreligious participants, and for different age groups are provided in Tables 1,2. Measures and the study design were evaluated and approved by an institutional review board prior to data collection to ensure compliance with Belmont Report ethical standards.

\section{Results}

Path analysis was applied to examine how frequency of attending religious services relates to people's sense of belongingness, how belongingness relates to perceived impact of COVID-19, and how religious service attendance, belongingness, and perceived COVID-19 impact relate to psychological distress. The analysis also controlled for gender and type of residence (measured in three categories: rural, 
Table 3 Frequency of participants engaging in social activities

\begin{tabular}{lcl}
\hline Activity & Percent "Yes" & Percent "No" \\
\hline Went to a restaurant & $25.1 \%$ & $74.9 \%$ \\
Went to a movie theater & $0.5 \%$ & $99.5 \%$ \\
Visited friends or family & $40.5 \%$ & $59.5 \%$ \\
Went to a social event & $3.1 \%$ & $96.9 \%$ \\
Attended a religious service & $5.0 \%$ & $95.0 \%$
\end{tabular}

Each question asked if the participant had done the activity during the prior week

Table 4 Bivariate correlations for main study variables

\begin{tabular}{lllllll}
\hline & 1 & 2 & 3 & 4 & 5 & 6 \\
\hline 1. DASS Score & - & - & - & - & - & - \\
2. Belongingness & $-.51^{* *}$ & - & - & - & - & - \\
3. COVID-19 Impact & $.29^{* *}$ & -.11 & - & - & - & - \\
4. Religious Service Attendance & .03 & $.15^{* *}$ & - & - & - & - \\
5. Sex & .02 & $.09^{*}$ & $.12^{*}$ & .00 & - & - \\
6. Type of Residence & .05 & -.11 & .09 & $-.27^{* *}$ & -.04 & - \\
\hline
\end{tabular}

Sex is coded as a dichotomous variable where $0=$ male, $1=$ female

$* p<.05, * * p<.01$

suburban, and urban) since evidence supports people in rural regions and women tend to be more involved in religious communities (e.g., Trzebiatowska \& Bruce, 2012). Age was explored in the model but reduced the model-fit statistics, so was omitted from the final analysis. Other demographic variables (e.g., racial/ethnic identity) were not included in the study since there was little reason to expect they would alter the associations between religion, perceived belongingness, and distress reduction. The main variables' bivariate correlations are presented in Table 4. The model diagram is displayed in Fig. 1, and the standardized coefficients are presented in Table 5. The model-fit statistics, reported at the bottom of Table 5 (RMSEA $=0.08$ and CFI $=0.93$ ), show good model fit (Acock, 2013). The model was appropriate considering all non-control variables used interval scales and scatterplots suggested linear relationships among study variables.

The analyses yield three primary findings. First, religious service attendance is significantly and positively related to belongingness. In other words, participants who more frequently attended religious services had a stronger sense of belonging $(\beta=0.15, p<0.001)$. Second, belongingness had a significant and negative relationship with perceived COVID-19 impact. People who reported greater belongingness were less likely to report experiencing significant life impact from COVID-19 $(\beta=-0.11, p<0.01)$. Third, participants with a greater sense of belonging were less likely to feel depression, anxiety, and stress $(\beta=-0.49, p<0.001)$. Conversely, religious service attendance by itself $(\beta=0.13, p<0.001)$ and heightened perceived impact from COVID-19 $(\beta=0.24, p<0.001)$ were positively related with depression, anxiety, and stress. The impact from the two demographic control variables, 


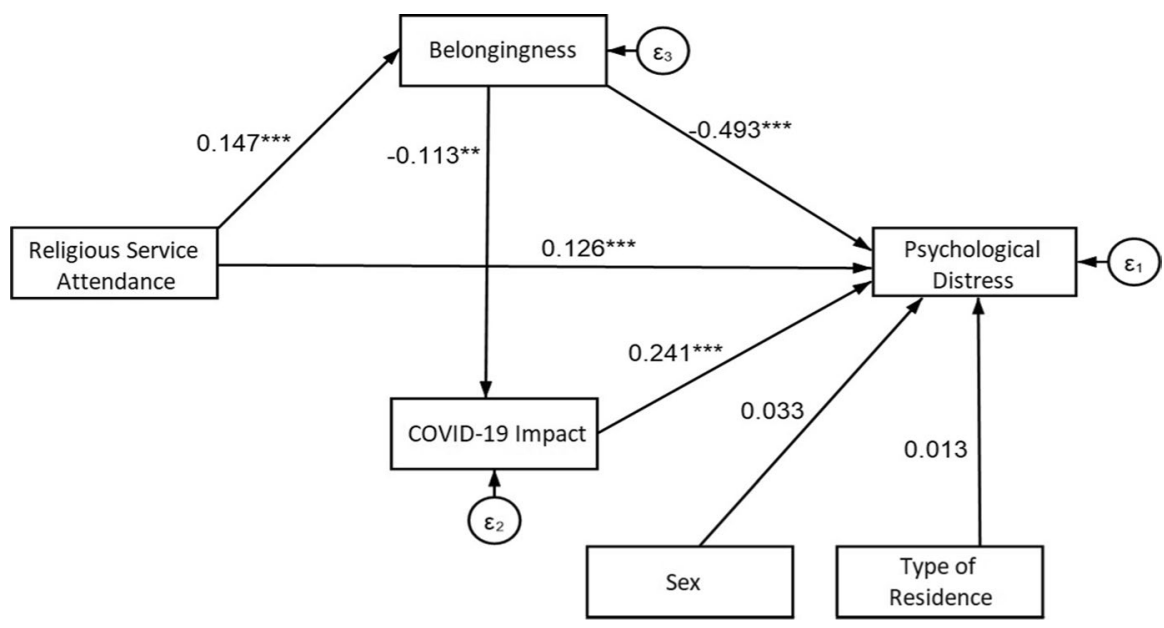

Fig. 1 Path analysis diagram. Based on theoretical rationale, the model predicts that people who report more frequent religious service attendance during the past year (before June 2020) experience greater belongingness, and this belongingness relates to diminished perceived impact from the COVID-19 pandemic and reduces symptoms of depression, anxiety, and stress. Note sex is coded $0=$ male, $1=$ female; urban/rural is coded $1=$ rural, $2=$ suburban, $3=$ urban

Table 5 Standardized coefficients of path analysis

\begin{tabular}{lllc}
\hline & Belongingness & COVID-19 Impact & Well-being \\
\hline $\begin{array}{l}\text { Standardized coefficients } \\
\text { Attendance of Religious }\end{array}$ & $0.147^{* * *}$ & - & \\
$\quad$ Services & - & $-0.113^{* *}$ & $0.126^{* * *}$ \\
Belongingness & - & - & $-0.493^{* * *}$ \\
COVID-19 Impact & - & - & $0.241^{* * *}$ \\
Female & - & - & 0.033 \\
Type of Residence & & & 0.013 \\
Model-Fit Statistics & 0.079 & & \\
RMSEA & 0.930 & & \\
CFI & &
\end{tabular}

$* p<0.05 ; * * p<0.01 ; * * * p<0.001$

gender and place of residence, were insignificant (see Table 5). ${ }^{2}$ Overall, the model variables together accounted for $32 \%$ of the observed variance in respondents' psychological distress $\left(R^{2}=0.32\right)$.

\footnotetext{
${ }^{2}$ We initially tested a model that also controlled for age, but it resulted in a model with poorer fit and was thus omitted from the final analysis.
} 


\section{Discussion}

The present study presents some of the first empirical results about how religion relates to psychological distress during the COVID-19 pandemic and offers new evidence of both theoretical and practical significance. Using data from an American sample, results supported two theoretically driven hypotheses. First, people reporting more frequent religious service attendance experience a heightened sense of belongingness, and heightened belongingness was associated with reduced psychological distress (Hypothesis 1). Second, people who felt greater belongingness tended to perceive that the pandemic had a less significant impact on their life (Hypothesis 2). Importantly, there was an opposite relationship between religious service attendance and psychological distress when not factoring-in belongingness. Frequent religious service attendance by itself was associated with greater psychological distress among participants. This reveals that religion's capability to buffer against psychological distress does not appear to be a mere result of direct physical contact and social support, but rather results from a more subjective sense of belongingness that is enhanced by religious community involvement. Furthermore, people who have greater sense of belongingness reported less perceived impact from the pandemic. These findings align well with key theoretical ideas about the relationship between religious involvement, coping, and psychological distress reduction.

Considerable empirical evidence supports that religious involvement relates to well-being (e.g., Balbuena et al., 2013; Keyes \& Reitzes, 2007; Koenig et al., 2012; Strawbridge et al., 2001; VanderWeele, 2017), but whether this relationship is primarily driven by direct social interactions or indirect perceived social benefits is less clear (see Ellison, 1991; Graham \& Haidt, 2010; Hill et al., 2011). Recent theoretical perspectives suggest that the religion-well-being association emerges from a combination of direct and indirect social factors (Aldwin et al., 2014), which the present study supports by showing that through belongingness religion relates to a reduction in psychological distress.

\section{The Role of Indirect Social Support}

Some previous research has also identified that religious service attendance does not relate to diminished psychological distress because of direct social support alone. For example, Steffen et al. (2017) found that intrinsic religiosity - a desire to live one's religion-was a primary mediator in the association between religious service attendance and reduction of anxiety and depressive symptoms. More recently Campos et al. (2020) identified that meaning in life is an additional mediator in the relationship between intrinsic religiosity and well-being. What these studies demonstrate is that religion relates to distress reduction and well-being enhancement due to multiple interacting factors including those that are objective and those that are subjective. 


\section{Belongingness and Distress Reduction}

There are many objective factors that may at least partly explain why religious service attendance and enhanced belongingness may relate to diminished distress. People who participate in religious services may have greater opportunity to receive instrumental social support, a more expansive social network, and enhanced identity as a member of a close-knit community (see Graham \& Haidt, 2010; Hill et al., 2011; Taylor et al., 2017). Together, these could promote a sense of belongingness and support, which would benefit well-being.

Some subjective factors that may explain the religious community involvement and distress reduction association include a greater subjective sense of belongingness, enhanced self-regulatory resources, and heightened perception of meaning in life (see Crescioni \& Baumeister, 2013; McCullough \& Willoughby, 2009; Park, 2013, 2017; VanTongeren et al., 2018). Indeed, there is increasing evidence that the meaning conferred by religious involvement may be a core mechanism explaining why religion can so potently help people cope and reduce their psychological distress during stressful events (Park, 2007). Some recent work has identified that during the COVID-19 pandemic, people who relied on positive religious coping tended to better maintain a sense of meaning in life and experienced less loneliness (Pirutinsky et al., 2020; Y1ldırım et al., 2021).

The current study's results fit with these ideas considering that belongingness is known to relate to meaning in life (e.g., Crescioni \& Baumeister, 2013) and that when people have an enhanced sense of meaning they are better able to cope with stress and restore perceived meaning when it is disrupted by distressing external events such as the COVID-19 pandemic (e.g., Michaels et al., 2013; Park, 2013; Park \& Baumeister, 2017). This interpretation is at least partly supported by the present results that demonstrate a heightened sense of belongingness related to less perceived impact from COVID-19 and reduced psychological distress. These relationships suggest that religious involvement, when it enhances perceived belongingness, may promote stress-buffering.

The finding that belongingness mediates the relationship between religious service attendance and diminished symptoms of anxiety, depression, and stress experienced by people enduring the COVID-19 pandemic also has some practical implications. Considering that $95 \%$ of those who reported attending religious services prior to the pandemic reported not doing so in the week prior to completing the survey, it is likely that most of the religious participants in the sample were following social distancing guidelines - a supposition supported by data in Table 3.

Thus, the findings allude to belongingness being a potential critical factor in helping people successfully cope with stress from the pandemic and social distancing. From the broader literature about how religious communities bind people into a meaningful collective (e.g., Graham \& Haidt, 2010), these results emphasize how it is important to find ways for people to retain a sense of community and connectedness even when isolating from others during pandemics. One way to promote sense of community would be to encourage online interaction with like-minded others or social groups. It is not clear from the present study if participants who were religious and social distancing were participating in virtual religious services, though. Some studies 
have demonstrated that online religious community involvement benefits well-being in ways similar to in-person religious community involvement (e.g., Okun \& Nimrod, 2020). Scholarship continues to emerge about how online communities fulfill people's religious needs during the pandemic (e.g., Frei-Landau, 2020; Parish, 2020). Presumably, other virtual community groups could be formed such as groups around common interests including hobbies, professional development networks, or informal virtual workgroups. Although such virtual interactions cannot fully replace face-to-face socialization, they may be able to at least provide some of the human interaction that is fundamental to human needs.

\section{Study Limitations}

This study is limited by its use of subjective measures and a cross-sectional design. As is often the case with social science research, subjective measures may be impacted by social desirability bias. In the current study, this may have led to participants overreporting how often they attend religious services or not honestly disclosing the extent of their anxiety, depressive, or stress-related symptoms. Furthermore, the cross-sectional design renders it impossible to identify causal relationships among the study variables. Also, some of the identified associations are somewhat small (see Table 5 and Fig. 1). This is not uncommon in social science research, though, as various behaviors and outcomes such as psychological distress are dependent on a substantial number of interacting variables. It should also be noted that this study relied on an American sample, which raises two additional limitations. First, the USA did not enact a unified national response to the pandemic. Social distancing guidelines varied between different states to include some states allowing social gatherings for religious services. Accordingly, the results may not be applicable to specific communities. Second, the pandemic impacts varied across countries, so the impacts may have been more or less severe in other nations. Thus, the present results may not generalize to other countries.

Finally, this study has some limitations related to measurement. Data did not include measurement of race/ethnicity or socioeconomic status to ensure survey brevity and because there was not a theoretical reason to assume such variables altered the relationship between religion, belongingness, and psychological distress. However, the pandemic's impacts were generally more substantial for vulnerable populations, such as those who are less affluent and are of minority status (e.g., Khatana \& Groeneveld, 2020). It is important for future studies to more closely examine whether and how these factors intersect the association between religious community involvement and psychological distress.

\section{Future Directions}

The present results suggest valuable directions for future research. Replicating this work in places where the pandemic was poorly controlled or testing these findings using archival data obtained during periods of significant distress with similar measures would be worthwhile. Additional studies could use longitudinal designs to track how the variables evolve over time. Such research could identify how experiences of 
psychological distress evolved during the COVID-19 pandemic for those who have previous involvement in religious communities versus those who did not. Qualitative research would also be beneficial to better understand how participation in religious services confers a heightened sense of subjective belongingness and how this relates to reduced risk of psychological distress.

\section{Conclusion}

In sum, the COVID-19 pandemic has had global consequences for people's psychological distress, and at least some of this relates to social distancing. The feelings of isolation and loneliness coupled with disruptions to perceived sense of control and life meaning can exacerbate feelings of anxiety, depression, and stress. Theoretically, religion's capacity to enhance coping through numerous pathways including via enhancing people's sense of belongingness can mitigate some of these deleterious effects, and some scholars have speculated on this (e.g., Koenig, 2020). However, empirical evidence for religion's role in helping people minimize psychological distress during COVID-19 remains lacking (Dein et al., 2020). This study addresses this critical gap in the literature and may be the first empirical study to provide evidence that people who more frequently attended religious services before the pandemic had greater perceived belongingness, and this belongingness related to both diminished perception of COVID-19 impact and diminished psychological distress. Together these findings validate the idea that the belongingness people gain by attending religious services, even in the past, helps minimize the psychological distress that so often accompanies stressful, uncontrollable life events.

Funding The authors received no funding for this study.

\section{Declarations}

Conflict of interest The authors declare no conflicts of interest.

Human and Animal Rights All research described in this manuscript was approved as meeting ethical standards for human subjects research (USF Protocol \#000903).

Informed Consent All participants provided informed consent before taking part in this study and were free to withdraw at any time.

\section{References}

Acock, A. C. (2013). Discovering structural equation modeling using Stata. Stata Press.

Ahmed, F., Zviedrite, N., \& Uzicanin, A. (2018). Effectiveness of workplace social distancing measures in reducing influenza transmission: A systematic review. BMC Public Health, 18, 518. https://doi. org/10.1186/s 12889-018-5446-1 
Aldwin, C. M., Park, C. L., Jeong, Y., \& Nath, R. (2014). Differing pathways between religiousness, spirituality, and health: A self-regulation perspective. Psychology of Religion and Spirituality, 6(1), 9-21. https://doi.org/10.1037/a0034416

Antony, M. M., Bieling, P. J., Cox, B. J., Enns, M. W., \& Swinson, R. P. (1998). Psychometric properties of the 42-item and 21-item versions of the depression anxiety stress scales in clinical groups and a community sample. Psychological Assessment, 10(2), 176-181. https://doi.org/10.1037/1040-3590. 10.2.176

Balbuena, L., Baetz, M., \& Bowen, R. (2013). Religious attendance, spirituality, and major depression in Canada: A 14-year follow-up study. Canadian Journal of Psychiatry, 58, 225-232. https://doi.org/ $10.1177 / 070674371305800408$

Brewer-Smyth, K., \& Koenig, H. G. (2014). Could spirituality and religion promote stress resilience in survivors of childhood trauma? Issues in Mental Health Nursing, 35(4), 251-256. https://doi.org/10. 3109/01612840.2013.873101

Byrd, K. R., Hageman, A., \& Isle, D. B. (2007). Intrinsic motivation and subjective well-being: The unique contribution of intrinsic religious motivation. The International Journal for the Psychology of Religion, 17(2), 141-156. https://doi.org/10.1080/10508610701244155

Byrd, K. R., Lear, D., \& Schwenka, S. (2000). Mysticism as a predictor of subjective well-being. The InternationalJournal for the Psychology of Religion, 10, 259-269. https://doi.org/10.1207/S1532 7582IJPR1004_04

Cacioppo, J. T., \& Cacioppo, S. (2014). Social relationships and health: The toxic effects of perceived social isolation. Social and Personality Psychology Compass, 8(2), 58-72. https://doi.org/10.1111/ spc3.12087

Campos, J., Bredemeier, J., \& Trentini, C. (2020). Meaning in life as a mediator of the relationship between intrinsic religiosity and depression symptoms. Trends in Psychology. https://doi.org/10. 1007/s43076-020-00036-0

Centers for Disease Control (2020). Household Pulse Survey: Mental Health. Accessed 13 August 2020 from: https://www.cdc.gov/nchs/covid19/pulse/mental-health.htm

Crescioni, A. W., \& Baumeister, R. F. (2013). The four needs for meaning, the value gap, and how (and whether) society can fill the void. In J. Hicks \& C. Routledge (Eds.), The experience of meaning in life: Classical perspectives, emerging themes, and controversies (pp. 3-16). Springer.

Dein, S., Loewenthal, K., Lewis, C. A., \& Pargament, K. I. (2020). COVID-19, mental health, and religion: An agenda for future research. Mental Health, Religion, and Culture, 23, 1-9. https://doi.org/ $10.1080 / 13674676.2020 .1768725$

Dunbar, R. I. M. (2020). Religiosity and religious attendance as factors in wellbeing and social engagement. Religion, Brain, and Behavior, 11(1), 17-26. https://doi.org/10.1080/2153599X.2020.17126 18

Ellison, C. G. (1991). Religious involvement and subjective well-being. Journal of Health and Social Behavior, 32, 80-99. https://doi.org/10.2307/2136801

Ellison, C. G., Gay, D. A., \& Glass, T. A. (1989). Does religious commitment contribute to individual lifesatisfaction?. Social Forces, 68(1), 100-123. https://doi.org/10.1093/sf/68.1.100

Frei-Landau, R. (2020). "When the going gets tough, the tough get - creative": Israeli Jewish religious leaders find religiously innovative ways to preserve community members' sense of belonging and resilience during the COVID-19 pandemic. Psychological Trauma: Theory, Research, Practice, and Policy, 12(S1), S258-S260. https://doi.org/10.1037/tra0000822

George, L., Ellison, C., \& Larsen, D. (2002). Explaining the relationships between religious involvement and health. Psychological Inquiry, 13, 190-200. https://doi.org/10.1207/S15327965PLI1303_04

González-Sanguino, C., Ausín, B., Castellanos, M. A., Saiz, J., López-Gómez, A., Ugidos, C., \& Muñoz, M. (2020). Mental health consequences during the initial stage of the 2020 Coronavirus pandemic (COVID-19) in Spain. Brain, Behavior, and Immunity, 87, 172-176. https://doi.org/10.1016/j.bbi. 2020.05 .040

Graham, J., \& Haidt, J. (2010). Beyond beliefs: Religions bind individuals into moral communities. Personality and Social Psychology Review, 14, 140-150. https://doi.org/10.1177/1088868309353415

Hill, T. D., Burdette, A. M., \& Idler, E. L. (2011). Religious involvement, health status, and mortality risk. In R. A. Settersen Jr. \& J. L. Angel (Eds.), Handbook of Sociology and Aging (pp. 533-546). Springer.

Holt-Lundstad, J., Smith, T. B., Baker, M., Harris, T., \& Stephenson, D. (2015). Loneliness and social isolation as risk factors for mortality: A meta-analytic review. Perspectives on Psychological Science, 10, 227-237. https://doi.org/10.1177/1745691614568352 
House, J. S., Landis, K. R., \& Umberson, D. (1988). Social relationships and health. Science, 241, 540545. https://doi.org/10.1126/science.3399889

Huang, Y., \& Zhao, N. (2020). Generalized anxiety disorder, depressive symptoms, and sleep quality during COVID-19 outbreak in China: A web-based cross-sectional survey. Psychiatry Research, 288, 112954. https://doi.org/10.1016/j.psyres.2020.112954

Keyes, C. L. M., \& Reitzes, D. C. (2007). The role of religious identity in the mental health of older working and retired adults. Aging and Mental Health, 11, 434-443. https://doi.org/10.1080/13607 860601086371

Khatana, S. A. M., \& Groeneveld, P. W. (2020). Health disparities and the coronavirus disease 2019 (COVID-19) pandemic in the USA. Journal of General Internal Medicine, 35, 2431-2432. https:// doi.org/10.1007/s11606-020-05916-w

Kim-Yeary, K. H., Ounpraseuth, S., Moore, P., Bursac, Z., \& Greene, P. (2012). Religion, social capital, and health. Review of Religious Research, 54, 331-347. https://doi.org/10.1007/s13644-011-0048-8

Koenig, H. G. (2020). Maintaining health and well-being by putting faith into action during the COVID-19 pandemic. Journal of Religion and Health, 59, 2205-2214. https://doi.org/10.1007/ s10943-020-01035-2

Koenig, H. G., King, D., \& Carlson, V. B. (2012). Handbook of religion and health (2nd ed.). Oxford University Press.

Krause, N., \& Wulff, K. M. (2005). Church-based social ties, a sense of belonging in a congregation, and physical health status. The International Journal for the Psychology of Religion, 15, 73-93. https:// doi.org/10.1207/s15327582ijpr1501_6

Li, L. Z., \& Wang, S. (2020). Prevalence and predictors of general psychiatric disorders and loneliness during COVID-19 in the United Kingdom. Psychiatry Research, 291, 113267. https://doi.org/10. 1016/j.psyres.2020.113267

Malone, G. P., Pillow, D. R., \& Osman, A. (2012). The general belongingness scale (GBS): Assessing achieved belongingness. Personality and Individual Differences, 52(3), 311-316. https://doi.org/10. 1016/j.paid.2011.10.027

Marroquín, B., Vine, V., \& Morgan, R. (2020). Mental health during the COVID-19 pandemic: Effects of stay-at-home policies, social distancing behavior, and social resources. Psychiatry Research, 293, 113419. https://doi.org/10.1016/j.psychres.2020.113419

McCullough, M. E., \& Willoughby, B. L. (2009). Religion, self-regulation, and self-control: Associations, explanations, and implications. Psychological Bulletin, 135(1), 69-93. https://doi.org/10. $1037 / \mathrm{a} 0014213$

Michaels, J. L., Parkin, S. S., \& Vallacher, R. R. (2013). Destiny is in the details: Action identification in the construction and deconstruction of meaning. In J. Hicks \& C. Routledge (Eds.), The experience of meaning in life: Perspectives from the psychological sciences (pp. 103-115). Springer.

Miller, G. (2011). Why loneliness is hazardous to your health. Science, 331(6014), 138-140. https://doi. org/10.1126/science.331.6014.138

Okun, S., \& Nimrod, G. (2019). Online religious communities and wellbeing in later life. Journal of Religion, Spirituality, and Aging. https://doi.org/10.1080/15528030.2019.1666333

Parish, H. (2020). The absence of presence and the presence of absence: Social distancing, sacraments, and the virtual religious community during the COVID-19 pandemic. Religions. https://doi.org/10. 3390/rel11060276

Park, C. L. (2007). Religiousness/spirituality and health: A meaning systems perspective. Journal of Behavioral Medicine, 30, 319-328. https://doi.org/10.1007/s10865-007-9111-x

Park, C. L. (2013). The meaning making model: A framework for understanding meaning, spirituality, and stress-related growth in health psychology. The European Health Psychologist, 15(2), 40-47.

Park, C. L. (2017). Religious cognitions and wellbeing: A meaning perspective. In M. D. Robinson \& M. Eids (Eds.), The happy mind: Cognitive contributions to well-being (pp. 443-458). Springer.

Park, J., \& Baumeister, R. (2017). Meaning in life and adjustment to daily stressors. The Journal of Positive Psychology, 12(4), 333-341. https://doi.org/10.1080/17439760.2016.1209542

Peteet, J. R. (2020). COVID-19 anxiety. Journal of Religion and Health, 59(5), 2203-2204. https://doi. org/10.1007/s10943-020-01041-4

Pirutinsky, S., Cherniak, A. D., \& Rosmarin, D. H. (2020). COVID-19, mental health, and religious coping among American Orthodox Jews. Journal of Religion and Health, 59(5), 2288-2301. https://doi. org/10.1007/s10943-020-01070-z 
Steffen, P. R., Masters, K. S., \& Baldwin, S. (2017). What mediates the relationship between religious service attendance and aspects of well-being? Journal of Religion and Health, 56, 158-170. https:// doi.org/10.1007/s10943-016-0203-1

Strawbridge, W. J., Shema, S. J., Cohen, R. D., \& Kaplan, G. A. (2001). Religious attendance increases survival by improving and maintaining good health behaviors, mental health, and social relationships. Annals of Behavioral Medicine, 23, 68-74. https://doi.org/10.1207/S15324796ABM2301_10

Taylor, R. J., Chatters, L. M., Lincoln, K., \& Woodward, A. T. (2017). Church-based exchanges of informal social support among African American. Race and Social Problems, 9(1), 53-62. https://doi. org/10.1007/s121552-017-9195-z

Trzebiatowska, M., \& Bruce, S. (2012). Why are women more religious than men? Oxford University Press.

Van Tongeren, D. R., DeWall, C. N., Green, J. D., Cairo, A. H., Davis, D. E., \& Hook, J. N. (2018). Selfregulation facilitates meaning in life. Review of General Psychology, 22(1), 95-106. https://doi.org/ 10.1037/gpr0000121

VanderWeele, T. J. (2017). Religion and health: A synthesis. In J. R. Peteet \& M. J. Balboni (Eds.), Spirituality and religion within the culture of medicine: From evidence to practice. Oxford University Press.

Wilder-Smith, A., \& Feedman, D. O. (2020). Isolation, quarantine, social distancing, and communitycontainment: Pivotal role for old-style public health measures in the novel coronavirus (2019-nCoV) outbreak. Journal of Travel Medicine, 27, 1-4. https://doi.org/10.1093/jtm/taaa020

Yıldırım, M., Kızılgeçit, M., Seçer, İ, Karabulut, F., Angın, Y., Dağcı, A., \& Çinici, M. (2021). Meaning in life, religious coping, and loneliness during the coronavirus health crisis in Turkey. Journal of Religion and Health. https://doi.org/10.1007/s10943-020-01173-7

Publisher's Note Springer Nature remains neutral with regard to jurisdictional claims in published maps and institutional affiliations. 